\title{
The Eighth Ukrainian Conference on Space Research
}

\author{
A.S. Parnovskiy \\ Candidate in physics and mathematics, researcher of Institute of Space Research of National \\ Academy of Sciences of Ukraine and National Space Agency of Ukraine, Kiev.
}

In the range of September 1-7, 2008 the National Center of Control and Test of Space Facilities located not far from the town of Evpatoria held the Eighth Ukrainian conference on space research. The conference organizers were the Institute of Space Research of National Academy of Sciences (NAS) of Ukraine and National Space Agency (NSA) of Ukraine, the National Center of Control and Test of Space Facilities of NSA of Ukraine by decision and under support of NSA of Ukraine.

Unlike the previous conferences a research area of this conference was more narrow and devoted exclusively to the problems of solar-terrestrial connection and space weather. The papers presented at the conference included the following sections: "Sun and solar wind" (10 papers), "Magnetosphere" (10 papers), “Ionosphere” (25 papers), "Space weather” (8 papers) and "Satellite experiments” (9 papers). Moreover, in the frames of Conference was conducted a round table concerning preparation of scientific space experiments "Ionosat" and "Potential".

Of great interest were the plenary papers of director of the Institute of Space Research of RAS Academician of RAS L.M. Zelenyi and the director of the Institute of Geomagnetism, Ionosphere and Radio Waves Propagation (IGIRWP) Doctor of physical and mathematical sciences V.D. Kuznetsov.

The Conference work involved more than 60 specialists representing 22 organizations - leading scientific centers of Ukraine, Russia and Byelorussia in the field of space research: Institute of Space Research of RAS, (IGIRWP), Byelorussian State University, Institute of Space Research of NAS of Ukraine and NSA of Ukraine, The Main Astronomic Observatory of NAN of Ukraine, Radio-Astronomy Institute of NAS of Ukraine, Institute of Ionosphere of NAS of Ukraine and Ministry of Education and

ISSN 1064-2315

(C) 2008 by Begell House Inc. 
Science of Ukraine GKB "Yuzhnoe”, Institute of Technical Mechanics of NAS of Ukraine and NSA of Ukraine, Kiev National Taras Shevchenko University, Kharkov National V.N. Karazin University and others.

The participants of the Conference noted a high level of presented papers and especially papers of young participants of the conference that were given this year financial support.

On the Conference completion the following decision was taken.

Considering the Eighth Conference on space research successful, make proposition to the Conference organizers to expand the participation of foreign specialists and give the Ninth Ukrainian conference on space research the status of international one.

To note the high scientific level of plenary papers, to recommend to continue the tradition of inviting leading specialists to deliver plenary lectures.

To consider directions of space research conducted in Ukraine, preparation and conducting of scientific space projects "Potentsial”, Ukrainian youth satellite and "Ionosat” to be prioritized.

To express gratitude to the National Center of Control and Tests of Space Facilities of NSA of Ukraine as well as Program and Organization committee for high level of Conference organization and conducting. 